in vivo $34: 3503-3509(2020)$

doi:10.21873/invivo.12191

\title{
Axillary Clearance Following Positive Sentinel Lymph Node Biopsy in Symptomatic Breast Cancer
}

\author{
HUDHAIFAH SHAKER, ZEINAB MAHATE, GRIT DABRITZ and MOHAMMED S. ABSAR \\ Department of Breast Surgery, Pennine Acute Hospitals NHS Trust, Manchester, U.K.
}

\begin{abstract}
Background/Aim: Symptomatic cancers display a different biological behaviour from screen-detected cancers, which may impact the management of axillary metastases. We aimed to determine the role of unselected axillary nodal clearance (ANC) in symptomatic patients with positive sentinel node biopsies (SNBS). Patients and Methods: A case-note review was performed on 95 symptomatic breast cancer patients who underwent ANC following positive SNB. Results: Thirty-eight (40\%) patients were treated with a mastectomy and 57 (60\%) with breast-conserving surgery. At ANC, 25 patients (26.3\%) showed evidence of further lymph node metastases, with 15 (60\%) having two or fewer macrometastases. The presence of more than 2 SNB macrometastases was associated with further ANC metastases $(p<0.001)$. The presence of further metastases at ANC was not associated with either reduced overall survival or disease-free survival. Conclusion: A number of symptomatic breast cancer patients with positive SNBs may be overtreated. Ongoing trials examining the management of low volume SNB macrometastases need to consider the symptomatic subgroup in their conclusions.
\end{abstract}

Sentinel lymph node biopsy (SNB) has replaced axillary lymph node clearance (ANC) as the surgical option of choice to stage the axilla in clinically node negative breast cancer patients. SNB is as reliable as ANC in staging patients without the associated increased morbidity of ANC (1). Traditionally, ANC was reserved for patients with evidence of metastases at SNB. However, because of the morbidity of axillary clearance and the fact that the majority of patients

This article is freely accessible online.

Correspondence to: Mohammed Absar, Department of Breast Surgery, Pennine Acute Hospitals NHS Trust, North Manchester General Hospital, Delaunays Road, Crumpsall, M8 5RB, U.K. Tel: +44 1617202608, e-mail: Mohammed.Absar@pat.nhs.uk

Key Words: Breast cancer, axillary surgery, sentinel node biopsy, symptomatic breast cancer. with positive SNBs do not have additional involved nodes, there has been an increasing move towards a more conservative management of these patients (2).

In addition, tumour-specific biology (e.g. cancer phenotype, genomic profiling) is playing an increasingly important role in determining the benefits of adjuvant therapy even in the presence of axillary metastases (3). For example, some cancer patients with favourable gene expression profiles may be spared chemotherapy despite having node-positive disease (4). To determine the risk or adverse effects of adjuvant chemotherapy may no longer be based on axillary staging alone, thus, it may be possible to reduce the need for automatic progression to axillary clearance in the presence of positive nodes in low-risk tumours. Although there is general consensus that ANC is not necessary in almost any patient with SNB-detected micrometastases (foci of tumour $>0.2 \mathrm{~mm}$ and $<2 \mathrm{~mm}$ ) or isolated tumour cells $(<0.2 \mathrm{~mm})(5)$, persistent clinical equipoise remains about the correct management of SNBs with positive macrometastases (defined as foci of $>2$ mm) (6-9).

Currently, patients with macrometastases still undergo axillary clearance or axillary radiotherapy, with the latter, however, shown to be non-inferior for selected patients with regards to local recurrence and possibly survival $(10,11)$. The ZO11 trial (12) attempted to answer specifically whether patients with one or two sentinel macrometastatic nodes at SNB could be safely treated without further ANC. In patients undergoing breast-conserving surgery and receiving whole breast radiotherapy, it was concluded that there was no difference in axillary recurrence, disease-free and overall survival between having an ANC and not having one (at 6.3 years follow-up). There were concerns, however, about the documentation of radiotherapy tangential fields, protocol deviations and early accrual closure (13) as well as whether these results could be applied to mastectomy patients not undergoing radiotherapy. This matter was brought up to the European Society of Medical Oncology (14) and the UK's National Institute for Health and Care Excellence (NICE) (15), who advised that Z011s findings should be confirmed by further trials. Several international trials, therefore, have intended to validate $\mathrm{Z} 011$ or answer the question regarding 
the management of SNB macrometastases in the wider population (e.g. mastectomy patients), such as POSNOC in the UK (16) and SENOMAC in Sweden (6).

Most completed and ongoing trials have recruited predominantly screen-detected cancers with symptomatic cancers forming a smaller portion in their cohort. Symptomatic cancer patients tend to be younger, more likely ER-negative and with worse survival compared to screen-detected cancers that may not be explained by lead-time bias alone (17), suggesting that symptomatic cancers behave differently. In addition, earlier cancer dissemination to the axilla is more likely in symptomatic cancers, with one study showing a fivefold increased risk of non-sentinel nodes at ANC in symptomatic compared to screen-detected cancers (18).

As a large non-screening United Kingdom National Health Service (NHS) unit, we sought to determine the outcome of ANC in our symptomatic patients who had a positive SNB at primary surgery. This was to examine the portion of patients who had further non-sentinel nodes involved and to examine our population in light of other studies, examining the issue of managing SNB metastases in clinically node-negative patients.

\section{Patients and Methods}

The study was a retrospective quality assurance assessment and required no approval from the ethical committee. Also, it was not registered on a clinical trials database.

The study population was identified from a prospectively maintained operating theatre database at the Pennines Acute Hospital NHS Trust, a non-screening breast surgery unit in Manchester, United Kingdom. All patients were women over the age of 18 diagnosed with invasive breast cancer (T1-3), who underwent sentinel node biopsy that was found to be positive (micro or micrometastases) and subsequently underwent axillary node clearance. The patients were treated between January 2008 and December 2017.

Data collection. Electronic patient records were accessed to obtain clinicopathological data including: i) age at surgery, ii) date of surgery, iii) histology, iv) pathological tumour category, v) number of positive lymph nodes, vi) oestrogen, receptor (ER) and progesterone receptor (PR) status, vii) human epidermal growth factor receptor 2 (HER2) status, viii) nuclear grade and ix) proliferation index (as measured by Ki-67 immunostaining). Micrometastases were defined as foci of tumour between $0.2 \mathrm{~mm}$ and $2 \mathrm{~mm}$ and macrometastases were defined as foci greater than $2 \mathrm{~mm}$ in size.

Treatment. At diagnosis, all patients underwent diagnostic mammography combined with breast and axillary lymph node ultrasound imaging. All patients had clinically and radiologically negative axillae and thus underwent a sentinel lymph node biopsy using combined radioisotope and blue dye. Patients who underwent any primary breast procedure with or without immediate reconstruction were included.

Up until 2014, all patients who had micro or macrometastatic disease at SNB underwent an axillary lymph node clearance after passing through the multi-disciplinary team meeting. After 2014, only patients with at least one lymph node with positive macrometastatic disease were recommended for lymph node clearance. After completion of surgical and adjuvant therapy patients were followed up on an annual basis for a total of 5 years and had mammography with or without breast ultrasonography every year.

Statistical analysis. Student's $t$-test and analysis of variance (ANOVA) was used to compare continuous variables. Relationships between categorical variables were compared using Chi-squared test. Recurrence-free and overall survival were graphically presented using Kaplan-Meier survival curves. The association between survival and clinicopathological variables was initially assessed using univariate Cox proportional hazards model. Statistical tests were performed using SPSS 22.0 for windows (IBM Corp. Released 2011. IBM SPSS Statistics for Windows, Version 22.0. Armonk, NY, USA). Values of $p<0.05$ were considered statistically significant. All reported $p$-Values are two-sided.

\section{Results}

Ninety-nine patients were identified. Four patients were excluded as they had been referred from breast cancer screening units and opted to have their treatments at our unit. This left 95 symptomatic patients with positive SNBs who subsequently had ANCs. The median age was 50 years (range $=32-78$ ). Mean tumour size was $24.0 \mathrm{~mm}$ (range $=2-70$ $\mathrm{mm})$. Thirty-eight $(40 \%)$ patients were treated with a mastectomy and 57 (60\%) with breast-conserving surgery; either a wide-local excision or therapeutic mammoplasty. Four patients $(4.3 \%)$ had neoadjuvant chemotherapy and 71 patients $(75.5 \%)$ had adjuvant chemotherapy. Nine patients (9.6\%) had adjuvant chemotherapy after their SNB but before their ANC. Clinicopathological details and oncological therapy are summarised in Table I.

At primary axillary surgery, a median of 3 axillary lymph nodes (range $=1-12$ ) were removed. A median of 1 positive (micro- or macrometastases) SNB node was identified with a range of 1 to 7 positive lymph nodes. Sixty-three SNBs $(66.3 \%)$ had macrometastases (+/- micrometastases) and 32 $(33.7 \%)$ had micrometastases alone.

At ANC, 25 patients (26.3\%) showed evidence of further non-sentinel lymph node metastases with 70 patients $(73.7 \%)$ having no evidence of further axillary metastases. Of these 25 patients, 4 patients $(16 \%)$ had micrometastases alone and 12 (40\%) had 1 or 2 further macrometastases at ANC. The total axillary burden of macrometastases (SNB+ANC) was calculated for all patients who had macrometastases at SNB. Out of 63 patients, $46(73 \%)$ patients had 1 or 2 macrometastases in total.

As patients with 1 or 2 nodes with macrometastases were considered to be low risk for further metastases at ANC [as per Z0011 (12) and ongoing POSNOC trial criteria (19)] we explored this subgroup further. At SNB, 52 patients $(82.5 \%)$ had 1 or 2 macrometastases at SNB. Of these, $12(23.1 \%)$ patients had further non-sentinel nodes at ANC and 40 (76.9\%) had none, even though one presented with micrometastases 
Table I. Baseline clinical-pathological characteristics and oncological treatments of patients who underwent axillary clearance after positive sentinel node biopsies.

\begin{tabular}{|c|c|c|c|}
\hline $\begin{array}{l}\text { Clinico-pathological } \\
\text { characteristics }\end{array}$ & $\mathrm{n}(\%) *$ & $\begin{array}{l}\text { Oncological } \\
\text { treatments }\end{array}$ & $\mathrm{n}(\%)^{*}$ \\
\hline Median age, years (range) & $50(26$ to 91$)$ & Primary breast operation & \\
\hline Mean invasive tumour size, $\mathrm{mm}(95 \% \mathrm{CI})$ & $24(2-70)$ & Breast conserving surgery & $57(60)$ \\
\hline Tumour pathological T Stage & & Mastectomy & $38(40)$ \\
\hline $\mathrm{T} 1$ & $48(50.5)$ & Neoadjuvant chemotherapy & \\
\hline $\mathrm{T} 2$ & $43(45.0)$ & Yes & $91(90.5)$ \\
\hline T3 & $3(4.2)$ & No & $4(4.2)$ \\
\hline Invasive grade & & Adjuvant chemotherapy & \\
\hline 1 & $13(13.7)$ & Yes & $72(75.8)$ \\
\hline 2 & $44(46.3)$ & No & $23(24.2)$ \\
\hline 3 & $38(40)$ & Adjuvant chemotherapy received between & \\
\hline Oestrogen receptor (ER) status & & SNB and completion ANC & \\
\hline Negative & $14(14.7)$ & Yes & $9(9.5)$ \\
\hline Positive & $81(85.3)$ & No & $86(90.5)$ \\
\hline HER2 receptor status & & Adjuvant radiotherapy & \\
\hline Negative & $77(81.1)$ & Yes & $68(71.6)$ \\
\hline Positive & $18(18.9)$ & No & $27(28.4)$ \\
\hline $\mathrm{Ki}-67$ & & Adjuvant endocrine therapy & \\
\hline Low $(<20 \%)$ & $48(51.1)$ & Yes & $81(85.3)$ \\
\hline \multirow[t]{4}{*}{ High $(>20 \%)$} & $47(48.9)$ & No & $14(14.7)$ \\
\hline & & Adjuvant Herceptin therapy & \\
\hline & & Yes & $18(18.9)$ \\
\hline & & No & $77(81.1)$ \\
\hline
\end{tabular}

*Unless otherwise stated. SNB: Sentinel node biopsy; ANC: axillary node clearance; HER2: human epidermal growth factor receptor 2; ER: oestrogen receptor.

alone. When considering the total axillary burden in this subgroup (SNB+ANC), 33 patients $(63.5 \%)$ had 1 macrometastatic node in total (i.e. had micrometastases at either SNB or ANC), 13 (25\%) had 2 macrometastases and the remainder $(11.5 \%)$ had 3 macrometastases or more. Further details of SNB and ANC findings are detailed in Table II.

The association between clinicopathological factors at SNB and the likelihood of involved non-sentinel metastases was examined. The presence of further metastases at ANC (versus negative ANC) correlated with tumour size $(p=0.02)$. When the four T3 tumours were excluded, the association between tumour size and likelihood of further non-sentinel nodes was $p=0.007$. There was no association between invasive grade, Ki67, ER or HER2 status and the likelihood of identifying involved non-sentinel nodes. The presence of more than 2 macrometastases at SNB was also significantly associated with an increased likelihood of further metastases at ANC $(p<0.001)$. There was no statistically significant association between the presence of macrometastases at SNB $v s$. micrometastases alone at SNB and the likelihood of ANC metastases, however, this may be due to the low number of patients with micrometastases at SNB that had further nonsentinel nodes. An association between clinicopathological characteristics and the likelihood of further non-sentinel nodes is shown in Table III.
During a median follow-up time of 79.8 months (range=7.2110.9 months), 11 patients $(11.6 \%)$ died, giving a median overall survival of 73.6 months (range=7.2-110.9 months).

Thirteen patients (13.7\%) developed distant cancer recurrence and 2 of these patients also developed local recurrence in the ipsilateral breast. Sixteen patients $(16.8 \%)$ developed lymphoedema during the follow-up period.

To examine whether there was a difference in survival between patients who had further axillary metastases at ANC and survival we used a cox proportional hazards model. Following univariate Cox proportional hazards analysis, invasive tumour grade (but not tumour size, receptor status or Ki67) was associated with reduced overall and diseasefree survival ( $p=0.01$ for both). There was no association between the presence of further metastases at ANC ( $v s$. tumour-free ANC) and reduced overall or disease-free survival, suggesting no difference between patients with negative and those with further axillary nodes involved (Figure 1).

\section{Discussion}

The management of the axilla in breast cancer remains a controversial topic with benefits of locoregional control balanced against the morbidity of performing a potentially 


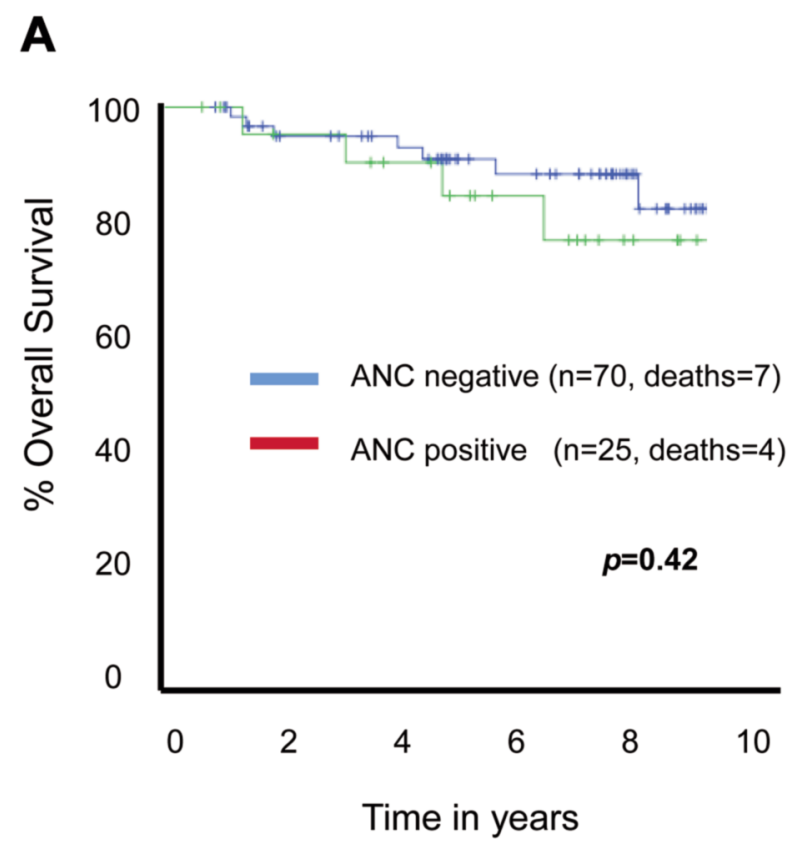

B

Figure 1. Kaplan-Meier survival curves for overall survival and disease-free survival. Association between presence (positive) and absence (negative) of further non-sentinel nodes at axillary nodal clearance (ANC) and overall survival $(A)$ and disease-free survival $(B)$.

Table II. Details of lymph node pathology at sentinel node biopsy and subsequent axillary node clearance ANC.

\begin{tabular}{lclc}
\hline $\begin{array}{l}\text { Pathological characteristics } \\
\text { at sentinel node biopsy }\end{array}$ & $\mathrm{n}(\%)^{*}$ & $\begin{array}{l}\text { Pathological characteristics } \\
\text { at axillary node clearance }\end{array}$ & $\mathrm{n}(\%)^{*}$ \\
\hline $\begin{array}{l}\text { Total number of SNB nodes removed, median (range) } \\
\text { Number of SNB positive }\end{array}$ & $3(1$ to 12$)$ & $\begin{array}{l}\text { Total number of nodes removed, median (range) } \\
\text { Involved non-sentinel nodes at ANC }\end{array}$ & $22(5-63)$ \\
$\quad$ Micrometastases alone & $32(33.7)$ & None & $70(73.7)$ \\
1 macrometastasis & $43(45.3)$ & Micrometastases alone & $4(4.2)$ \\
2 macrometastases & $9(9.5)$ & Macrometastases & $21(22.1)$ \\
$>2$ macrometastasis & $11(11.1)$ & Extracapsular spread & $3(3.2)$ \\
Extracapsular spread & $15(15.8)$ & Yes & $92(96.8)$ \\
Yes & $80(84.2)$ & No & \\
No & & \\
\hline
\end{tabular}

*Unless otherwise stated. SNB: Sentinel node biopsy; ANC: axillary node clearance.

unnecessary ANC. There is currently a treatment paradigm shift towards a more conservative approach to the management of positive axillary lymph nodes with a general decline in the number of patients receiving ANC after positive SNBs in the last decade (20).

However, there still remains debate about the safety of avoiding ANC in patients with macrometastases. Despite concerns about the generalisability of the Z011 results (13), some institutions in the USA have managed patients who meet the Z0011 criteria with conservative management alone (21), but this has not been in the case in Europe. Multiple ongoing trials are attempting to address this question (6).
In this single-centre study, we reviewed our heterogenous cohort of symptomatic patients who had undergone an ANC following positive SNB. We included patients who had undergone breast-conserving surgery or mastectomy. We found that just over $24 \%$ of patients had further non-sentinel node metastases at ANC. In patients who had only 1 or 2 macrometastases, only $17.5 \%$ of patients had further nodes involved. These numbers suggest that we are potentially overtreating $80 \%$ of our patients with unnecessary axillary node clearance. In addition, at least $16.8 \%$ of our patients developed lymphoedema during the follow-up period and this portion has to be considered in the context of the percentage of T1-2 
Table III. Univariate analysis comparing patients who had further involved non-sentinel nodes to those who had no further metastases at ANC.

\begin{tabular}{|c|c|c|c|}
\hline $\begin{array}{l}\text { Pathological } \\
\text { characteristics }\end{array}$ & $\begin{array}{c}\text { No involved } \\
\text { sentinel nodes } \\
\text { at ANC, } \mathrm{n}=70 \\
\mathrm{n}(\%)^{*}\end{array}$ & $\begin{array}{c}\text { Involved } \\
\text { sentinel nodes } \\
\text { at } \mathrm{ANC}, \mathrm{n}=25 \\
\mathrm{n}(\%)^{*}\end{array}$ & $p$-Value \\
\hline $\begin{array}{l}\text { Mean age at diagnosis } \\
\text { Years (range) }\end{array}$ & $52.4(26-91)$ & $49.7(32-78)$ & 0.54 \\
\hline $\begin{array}{l}\text { Mean pathological } \\
\text { tumour size mm (range) }\end{array}$ & $22.3(2-56)$ & $28.7(5-70)$ & 0.02 \\
\hline ER status & & & 0.55 \\
\hline Negative & $11(15.7)$ & $3(12)$ & \\
\hline Positive & $59(84.3)$ & $22(88)$ & \\
\hline HER2 Status & & & 0.12 \\
\hline Negative & $58(82.9)$ & $19(76)$ & \\
\hline Positive & $12(17.1)$ & $6(24)$ & \\
\hline Invasive tumour grade & & & 0.24 \\
\hline 1 & $11(15.7)$ & $2(8)$ & \\
\hline 2 & $29(41.4)$ & $16(64)$ & \\
\hline 3 & $31(42.8)$ & $7(28)$ & \\
\hline Ki67 & & & 0.24 \\
\hline Low $(<20 \%)$ & $33(68.8)$ & $15(31.3)$ & \\
\hline High $(>20 \%)$ & $39(80.4)$ & $7(19.6)$ & \\
\hline \multicolumn{4}{|l|}{$\begin{array}{l}\text { Number of nodes } \\
\text { removed at ANC }\end{array}$} \\
\hline Median (range) & $21(5-55)$ & $23(9-63)$ & 0.28 \\
\hline Metastases at SNB & & & 0.14 \\
\hline Micrometastases alone & $27(84.4)$ & $5(15.6)$ & \\
\hline Macrometastases & $43(69.3)$ & $20(31.7)$ & \\
\hline Macrometastases at SNB & & & 0.003 \\
\hline 1 or 2 macrometatases & $40(76.9)$ & $12(23.1)$ & \\
\hline$>2$ macrometstases & $3(27.3)$ & $8(72.7)$ & \\
\hline Extracapsular spread** & & & 0.21 \\
\hline Yes & $35(72.9)$ & $13(27.1)$ & \\
\hline No & $8(53.3)$ & $7(46.7)$ & \\
\hline
\end{tabular}

*Unless otherwise stated. **In subgroup with macrometastases at SNB. SNB: Sentinel node biopsy; ANC: axillary node clearance; HER2: human epidermal growth factor receptor 2; ER: oestrogen receptor.

patients (18\%) who had 2 or fewer macrometastases at ANC.

During a median follow-up period of 79.8 months [comparable to other studies $(12,21,22)]$ we also showed that there may be no survival advantage in patients who had no further involved non-sentinel nodes compared to those with further metastases. In particular, 44\% (11/25) of patients who did have additional non-sentinel nodes bore either only one macrometastasis or micrometastases alone. The additional removal of isolated macrometastases or micrometastases may not confer additional clinical benefit as the majority of these patients also went on to have adjuvant chemotherapy + /- endocrine therapy.

However, it would imply that staging of the axilla is helpful prognostically and should help direct treatment taking also into account the tumour biology. These data point towards the notion that clearance does not add any survival benefit. This is, of course, only based on a single centre and it's difficult to know its relevance until trials, such as POSNOC, have concluded.

As shown in previous studies, tumour size and number of positive macrometastases are the most significant risk factors for further non-sentinel node metastases $(12,22)$ and this was demonstrated in our cohort, where larger tumours and $>2$ macrometastases were significant predictors of further non-sentinel nodes.

Z0011 focused only on patients undergoing BCS whilst our cohort also included mastectomy patients (12). When considering only our BCS patients (the majority in our cohort) a similar percentage of non-sentinel nodes was found as in the Z011 cohort $(27.3 \%$ vs. $21.1 \%$ in ours), demonstrating similarities in this population in terms of low axillary burden.

Yun et al., in a retrospective series, focused on a cohort of 214 patients who had undergone mastectomy and had positive SNBs (17). This group found significantly worse OS in patents who had SNB alone compared to those who had axillary radiation or ANC. Despite this, $23 \%$ of patients in the SNB-alone group had T3 or T4 tumours compared to $5.3 \%$ in our cohort. POSNOC, amongst other trials, include patients managed by breast-conserving surgery or mastectomy and allow application to a heterogenous group, such as ours.

All patients in our cohort were symptomatic non-screendetected cancers. Symptomatic cancer is a poor prognostic factor for survival compared to screen-detected cancer (23). Although this has been partially explained by lead-time bias, some researchers have found it to be independent of tumour biology and age (24). In the context of a cohort of patients who are all clinically node-negative but SNB-positive, it could be pertinent that these patients should be considered differently from screen-detected or mixed populations. If screen-detected cancers include a subgroup of clinically insignificant, slower growing cancers, this could indicate a need for a more aggressive axillary treatment in patients with symptomatic cancers or at least a more cautious application of trials, such as Z0011 or POSNOC.

In a large case series of 773 patients with micrometastases, there was no significance in the number of non-sentinel nodes found in symptomatic compared to screen-detected cancers (18.5\% vs. $17.5 \%$ ) (25), however, another series of 140 patients have found a five-fold increased risk of non-sentinel node metastases after micrometastases at SNB (18). Farshid et al. have, similarly, demonstrated that symptomatic cancers have a greater portion of non-sentinel node metastases, however, this was not significant on multivariate analysis (26).

Another factor that needs to be considered when treating breast cancer patients is differences in pre-operative axillary ultrasound, which was not required in the Z0011 trial (12) 
but is a standard practice in the UK (15). The argument for those that advocate selective axillary ultrasound is that some ultrasound-positive patients may have low axillary burden and could be spared an ANC if they instead went to SNB (27). Although the discussion of axillary ultrasound is a separate issue, the UK practice of pre-operative ultrasound may increase the safety of conservative management of SNB-positive patients with low risk tumours as any patients with clinically or radiologically negative axillae would have a lower burden of disease prior to an SNB

Using current guidelines, our data shows that in our cohort of symptomatic cancers with clinically- and ultrasoundnegative axillae a large portion of symptomatic breast cancer patients with positive SNBs may be overtreated. Ongoing trials examining the management of low volume SNB macrometastases need to separately consider the symptomatic subgroup for drawing their conclusions.

\section{Conflicts of Interest}

None of the Authors have any conflicts of interest to declare.

\section{Authors' Contributions}

HS: study design, data collection and analysis, manuscript writing; ZM: data collection, data analysis, manuscript proofreading; GD: concept creation, data analysis, manuscript writing, proofreading, manuscript editing; MA - concept creation, manuscript writing, proofreading, manuscript editing.

\section{References}

1 Veronesi U, Paganelli G, Viale G, Luini A, Zurrida S, Galimberti V, Intra M, Veronesi P, Robertson C, Maisonneuve P, Renne G, De Cicco C, De Lucia F and Gennari R: A randomized comparison of sentinel-node biopsy with routine axillary dissection in breast cancer. N Engl J Med 349(6): 546-553, 2003. PMID: 12904519. DOI: 10.1056/NEJMoa012782

2 Yan M, Abdi MA and Falkson C: Axillary management in breast cancer patients: A comprehensive review of the key trials. Clin Breast Cancer 18(6): e1251-e1259, 2018. PMID: 30262257. DOI: $10.1016 /$ j.clbc.2018.08.002

3 Hamdan D, Nguyen TT, Leboeuf C, Meles S, Janin A and Bousquet G: Genomics applied to the treatment of breast cancer. Oncotarget 10(46): 4786-4801, 2019. PMID: 31413819. DOI: 10.18632/oncotarget.27102

4 Matikas A, Foukakis T, Swain S and Bergh J: Avoiding overand undertreatment in patients with resected node-positive breast cancer with the use of gene expression signatures: Are we there yet? Ann Oncol 30(7): 1044-1050, 2019. PMID: 31131397. DOI: 10.1093/annonc/mdz126

5 Gnant M, Harbeck N and Thomssen C: St. Gallen 2011: Summary of the consensus discussion. Breast Care (Basel) 6(2): 136-141, 2011. PMID: 21633630. DOI: 10.1159/000328054

6 Henke G, Knauer M, Ribi K, Hayoz S, Gerard MA, Ruhstaller T, Zwahlen DR, Muenst S, Ackerknecht M, Hawle H, Fitzal F, Gnant M, Matrai Z, Ballardini B, Gyr A, Kurzeder C and Weber
WP: Tailored axillary surgery with or without axillary lymph node dissection followed by radiotherapy in patients with clinically node-positive breast cancer (taxis): Study protocol for a multicenter, randomized phase-iii trial. Trials 19(1): 667, 2018. PMID: 30514362. DOI: 10.1186/s13063-018-3021-9

7 de Boniface J, Schmidt M, Engel J, Smidt ML, Offersen BV and Reimer T: What is the best management of cn0pn1(sn) breast cancer patients? Breast Care (Basel) 13(5): 331-336, 2018. PMID: 30498417. DOI: 10.1159/000491704

8 Morrow M, Jagsi R, McLeod MC, Shumway D and Katz SJ: Surgeon attitudes toward the omission of axillary dissection in early breast cancer. JAMA Oncol 4(11): 1511-1516, 2018. PMID: 30003237. DOI: 10.1001/jamaoncol.2018.1908

9 Gera R, Kasem A and Mokbel K: Can complete axillary node dissection be safely omitted in patients with early breast cancer when the sentinel node biopsy is positive for malignancy? An update for clinical practice. In Vivo 32(6): 1301-1307, 2018. PMID: 30348682. DOI: 10.21873/invivo.11380

10 Savolt A, Peley G, Polgar C, Udvarhelyi N, Rubovszky G, Kovacs E, Gyorffy B, Kasler M and Matrai Z: Eight-year follow up result of the otoasor trial: The optimal treatment of the axilla - surgery or radiotherapy after positive sentinel lymph node biopsy in early-stage breast cancer: A randomized, single centre, phase iii, non-inferiority trial. Eur J Surg Oncol 43(4): 672-679, 2017. PMID: 28139362. DOI: 10.1016/j.ejso.2016.12.011

11 Donker M, van Tienhoven G, Straver ME, Meijnen P, van de Velde CJ, Mansel RE, Cataliotti L, Westenberg AH, Klinkenbijl JH, Orzalesi L, Bouma WH, van der Mijle HC, Nieuwenhuijzen GA, Veltkamp SC, Slaets L, Duez NJ, de Graaf PW, van Dalen T, Marinelli A, Rijna H, Snoj M, Bundred NJ, Merkus JW, Belkacemi Y, Petignat P, Schinagl DA, Coens C, Messina CG, Bogaerts $J$ and Rutgers EJ: Radiotherapy or surgery of the axilla after a positive sentinel node in breast cancer (eortc 10981-22023 amaros): A randomised, multicentre, open-label, phase 3 non-inferiority trial. Lancet Oncol 15(12): 1303-1310, 2014. PMID: 25439688. DOI: 10.1016/s1470-2045(14)70460-7

12 Giuliano AE, Hunt KK, Ballman KV, Beitsch PD, Whitworth PW, Blumencranz PW, Leitch AM, Saha S, McCall LM and Morrow M: Axillary dissection vs. no axillary dissection in women with invasive breast cancer and sentinel node metastasis: A randomized clinical trial. Jama 305(6): 569-575, 2011. PMID: 21304082. DOI: 10.1001/jama.2011.90

13 Gatzemeier W and Mann GB: Which sentinel lymph-node (sln) positive breast cancer patient needs an axillary lymph-node dissection (alnd)-acosog z0011 results and beyond. Breast 22(3): 211-216, 2013. PMID: 23478200. DOI: 10.1016/j.breast.2013.02. 001

14 Senkus E, Kyriakides S, Ohno S, Penault-Llorca F, Poortmans P, Rutgers E, Zackrisson S and Cardoso F: Primary breast cancer: Esmo clinical practice guidelines for diagnosis, treatment and follow-up. Ann Oncol 26 Suppl 5: v8-30, 2015. PMID: 26314782. DOI: $10.1093 /$ annonc/mdv298

15 NICE: (National institute for health and care excellence) early and locally advanced breast cancer: Diagnosis and management. [b] evidence reviews for management of the positive axilla (nice guideline ng101). Retrieved from https://wwwniceorguk/ guidance/ng101/evidence/b-management-of-positive-axilla-pdf4904666607 
16 Goyal A, Dodwell D, Reed MW and Coleman RE: Axillary treatment in women with one or two sentinel nodes with macrometastases: More evidence is needed to inform practice. $\mathrm{J}$ Clin Oncol 32(34): 3902, 2014. PMID: 25245444. DOI: 10.1200/jco.2014.57.3717

17 Dawson SJ, Duffy SW, Blows FM, Driver KE, Provenzano E, LeQuesne J, Greenberg DC, Pharoah P, Caldas C and Wishart GC: Molecular characteristics of screen-detected $v s$. symptomatic breast cancers and their impact on survival. Br J Cancer 101(8): 1338-1344, 2009. PMID: 19773756. DOI: $10.1038 /$ sj.bjc. 6605317

18 Grabau D, Dihge L, Ferno M, Ingvar C and Ryden L: Completion axillary dissection can safely be omitted in screen detected breast cancer patients with micrometastases. A decade's experience from a single institution. Eur J Surg Oncol 39(6): 601-607, 2013. PMID: 23579175. DOI: 10.1016/j.ejso. 2013.03.012

19 Goyal A and Dodwell D: Posnoc: A randomised trial looking at axillary treatment in women with one or two sentinel nodes with macrometastases. Clin Oncol (R Coll Radiol) 27(12): 692-695, 2015. PMID: 26254841. DOI: 10.1016/j.clon.2015.07.005

20 Gondos A, Jansen L, Heil J, Schneeweiss A, Voogd AC, Frisell J, Fredriksson I, Johansson U, Tvedskov TF, Jensen MB, Balslev E, Hartmann-Johnsen OJ, Sant M, Baili P, Agresti R, van de Velde T, Broeks A, Nogaret JM, Bourgeois P, Moreau M, Matrai Z, Savolt A, Nagy P, Kasler M, Schrotz-King P, Ulrich C and Brenner H: Time trends in axilla management among early breast cancer patients: Persisting major variation in clinical practice across european centers. Acta Oncol 55(6): 712-719, 2016. PMID: 26878397. DOI: 10.3109/0284186x.2015.1136751

21 Morrow M, Van Zee KJ, Patil S, Petruolo O, Mamtani A, Barrio AV, Capko D, El-Tamer M, Gemignani ML, Heerdt AS, Kirstein L, Pilewskie M, Plitas G, Sacchini VS, Sclafani LM, Ho A and Cody HS: Axillary dissection and nodal irradiation can be avoided for most node-positive z0011-eligible breast cancers: A prospective validation study of 793 patients. Ann Surg 266(3): 457-462, 2017. PMID: 28650355. DOI: 10.1097/sla.0000000 000002354
22 Fu Y, Chung D, Cao MA, Apple S and Chang H: Is axillary lymph node dissection necessary after sentinel lymph node biopsy in patients with mastectomy and pathological $\mathrm{n} 1$ breast cancer? Ann Surg Oncol 21(13): 4109-4123, 2014. PMID: 25081336. DOI: $10.1245 / \mathrm{s} 10434-014-3814-3$

23 Allgood PC, Duffy SW, Kearins O, O’Sullivan E, Tappenden N, Wallis MG and Lawrence G: Explaining the difference in prognosis between screen-detected and symptomatic breast cancers. Br J Cancer 104(11): 1680-1685, 2011. PMID: 21540862. DOI: $10.1038 / b j c .2011 .144$

24 Gill PG, Farshid G, Luke CG and Roder DM: Detection by screening mammography is a powerful independent predictor of survival in women diagnosed with breast cancer. Breast 13(1): 15-22, 2004. PMID: 14759711. DOI: 10.1016/s0960-9776(03) 00169-3

25 Tvedskov TF, Jensen MB, Balslev E, Garne JP, Vejborg I, Christiansen P, Ejlertsen B and Kroman N: Risk of non-sentinel node metastases in patients with symptomatic cancers compared to screen-detected breast cancers. Acta Oncol 55(4): 455-459, 2016. PMID: 26452696. DOI: 10.3109/0284186x.2015.1094186

26 Farshid G, Pradhan M, Kollias J and Gill PG: A decision aid for predicting non-sentinel node involvement in women with breast cancer and at least one positive sentinel node. Breast 13(6): 494501, 2004. PMID: 15563857. DOI: 10.1016/j.breast.2004.08.005

27 Ahmed M, Jozsa F, Baker R, Rubio IT, Benson J and Douek M: Meta-analysis of tumour burden in pre-operative axillary ultrasound positive and negative breast cancer patients. Breast Cancer Res Treat 166(2): 329-336, 2017. PMID: 15563857. DOI: $10.1007 / \mathrm{s} 10549-017-4405-3$
Received August 8, 2020

Revised September 7, 2020 Accepted September 11, 2020 